\title{
Paradoxical Bilateral Asymmetry in Bone Size and Bone Mass in the Hand
}

\author{
STANLEY M. GARN, GILBERT H. MAYOR 1 AND HELEN A. SHAW \\ Center for Human Growth and Development and Department of Internal \\ Medicine, The University of Michigan, Ann Arbor, Michigan 48109
}

\section{KEY WORDS Bone mass - Hand asymmetry - Radiogrammetry.}

\begin{abstract}
Among 227 chronic renal disease patients, micrometer caliper radiogrammetric measurements of the second metacarpal at midshaft showed the right metacarpal to be larger (with greater bone area) and with a greater cortical area than the left second metacarpal, both in 208 right-handed individuals and in 19 left-handed individuals. This direction of asymmetry was individually characteristic of the majority of individuals, whether right-handed, left-handed or ambidextrous.
\end{abstract}

In the course of studies on bone loss in chronic renal disease patients (CRD) using micrometer caliper measurements on postero-anterior hand radiographs, we became concerned with bilateral (left-right) asymmetry for two practical reasons. The first source of concern stemmed from the fact that approximately $10 \%$ of the patients were left-handed, as judged from handpreference records, whereas the standards used for comparison were left-handed standards (cf. Garn, '70). The second source of concern arose from the location of indwelling fistulas in dialyzed patients and the possibility that the location of the fistulas as well as handedness might both have to be taken into account. Accordingly, we explored bilateral hand asymmetry in 227 patients and found evidence for a small but statistically-significant left-right difference in bone area, cortical area (bone mass) and percent cortical area.

Prime bone measurements on these patients (most of whom were adults) included the total subperiosteal diameter (T), and medullary cavity width (M) as measured on the second metacarpal at midshaft, using a standardized tube-to-film distance throughout (Garn, '70; Garn et al., '71). Total area (TA), cortical area (CA) and percent cortical area (PCA) were then computer calculated on an individual basis for each patient, for each side separately. The left-right differences $(d)$ were also individually computer calculated, and then the $d$ values were tested for significance by tests appropriate for matched pairs (Dixon and Massey, '69). Since all comparisons were intra-individual though inter-side, the 118 males and 117 females were not separately tabulated.

As shown in table 1, among 208 righthanded patients, bone area (TA) proved significantly larger in the right side than on the left $(\mathrm{t}=5.3)$. In similar fashion, cortical area (CA) also proved larger in the "dominant" (right) hand in these righthanded patients $(t=2.5)$. In contrast, percent cortical area (PCA) was higher on the left or smaller side, in these right-dominant CRD patients of both sexes $(t=3.1)$. On an individual basis, and excluding cases where the measurements were identical on both sides, 129 of the right-handed patients had greater bone areas on the right side and 64 on the left; 113 evidenced greater cortical area on the right side and 82 on the left.

Turning to the 19 left-handed ("leftdominant") patients, the same trends were also found (table 1). The left-handed patients had larger bone areas on the right side, larger cortical areas or bone masses on the right side and, like the right dominant patients, larger percent cortical areas (PCA) on the left side. A smaller group of five ambidextrous patients not originally considered also displayed a larger bone

\footnotetext{
1 Current address: Dr. Gilbert Mayor, Assistant Pro fessor, Department of Medicine and Department of Surgery, College of Human Medicine, B220, Life Sciences Building, Michigan State University, East Lansing, Michigan 48824.
} 
TABLE 1

Bilateral (fefi-right) hand asymmetry in 227 renal patients

\begin{tabular}{|c|c|c|c|c|c|}
\hline \multirow{2}{*}{$\begin{array}{c}\text { Metacapal } \\
\text { measurement }\end{array}$} & \multirow[b]{2}{*}{ Right } & \multirow[b]{2}{*}{ I eft } & \multicolumn{2}{|c|}{ Difference 1} & \multirow[b]{2}{*}{12} \\
\hline & & & Wean & S.F. & \\
\hline \multicolumn{6}{|c|}{208 right-handed patients } \\
\hline Total area $\left(\mathrm{mm}^{2}\right)$ & 61.7 & 59.5 & 2.3 & 0.4 & 5.3 \\
\hline Cortical area $\left(\mathrm{mm}^{2}\right)$ & 48.6 & 47.6 & 1.0 & 0.4 & 2.5 \\
\hline Percent cortical area & 79.4 & 80.5 & -1.2 & 0.4 & 3.1 \\
\hline \multicolumn{6}{|c|}{19 left handed patients } \\
\hline Total area $\left(\mathrm{mm}^{2}\right)$ & 60.2 & 59.3 & 0.9 & 1.2 & 0.7 \\
\hline Cortical area $\left(\mathrm{mm}^{2}\right)$ & 47.0 & 46.4 & 0.6 & 1.3 & 0.4 \\
\hline Percent cortical areal & 78.9 & 79.3 & -0.4 & 1.4 & 0.3 \\
\hline
\end{tabular}

1 Computer-calculated on an indivadual basis prior to rounding-off

- Calculated as the difference between paired values.

area and a larger bone mass on the right side. Paradoxically, therefore hand dominance or "handedness" does not seem to be a major factor in the tendency toward larger bone areas and bone masses on the right side.

Exact literature parallels are not avail able, whether in radiogrammetric comparisons of the forearm (Buskirk et al., 56) or by direct-photon absorptiometry (cf. Wat son, 73). In the latter study, the dominant side proved to have larger bone widths and bone masses, but handedness was not specifically partitioned. We al so have available direct-photon absorptiometric measurements of the forearm of 184 patients, but with rather inconclusive results (insofar as statistical significance is concerned) and with positive but low-order corrclations between the magnitudes of bilateral asym metry in the hand and in the forearm.

Now these left-right differences in crosssectional area (TA), cortical mass (CA) and percent of compact bone (PCA) are all small, and for many purposes may well be ignored. By every measure we have employed, including direct-photon absorptiometry, bone loss is considerable in these chronic renal disease patients, and it makes little difference whether the "scans" and the radiographs are made on the right side or the left. However, with the present evidence for a small but systematic difference between the sides, it makes sense to measure the left side uniformly if left-side reference norms are employed.

Still it is intriguing that the right sicte tends to be the larger side, even in patients whose preferred hand is the left (i.e., "left dominance"). This may be a peculiarity of the patient group studied, including trans plant and dialysis patients, and it may still be an accident of sampling. and it may reflect the fact that left-dominant individuals actually employ their right hands to a greater extent. However, in a much earlier and hitherto unpublished study, we found that left-handed normal subjects were not dimensionally smaller in the left second metacarpal, and, therefore, developed norms and standards based on the left hand. throughout.

\section{ACKNOWLEDGMENTS}

Work described in this paper was supported, in part, from Grant HD 07134 from the National Institutes of Health and grants from the Michigan Association of Regional Medical Programs and from the Kidney Foundation of Michigan.

Many of the Cameron-Norland measurements involved in this study were completed by Thomas Sanchez.

\section{LITERATURE CITED}

Buskirk, E. R. K. L. Andersen and J. Brozek 1956 Unilateral activity and bone and muscle development in the forearm. Res. Quart., 27 $127-131$

Dixon, W. J., and F. J. Massey, Jr. 1969 Introduction to Statistical Analysis. Third ed. Mc. Graw-Hill, Inc., New York, p. 116.

Garn, S. M. 1970 The Earlier Gain and Later Loss of Cortical Bone. C. C Thomas, Springfield.

Garn, S. M., A. K. Poznanski and J. M. Nagy 1971 Bone measurement in the differential diagnosis of osteopenia and osteoporosis. Radiol ogy, 100: 509-518.

Watson, R. C. 1973 Bone growth and physical activity in young males. In: International Conference on Bone Mineral Measurement. R. B Mazess, ed. U.S. Dept of HEW, U.S. Govern ment Printing Office, Washington. D.C. pp. $380-386$. 